\title{
MODIFIKASI HOMOPOLIMER POLI (VINIL ASETAT) DENGAN VARIABEL HIDROFOBISITAS EMULSIFIER UNTUK APLIKASI PERKAYUAN
}

\author{
Rony Pasonang Sihombing ${ }^{1}$, Agustinus Ngatin ${ }^{1, *}$ \\ ${ }^{1}$ Jurusan Teknik Kimia, Politeknik Negeri Bandung \\ Jln. Gegerkalong Hilir, Ds. Ciwaruga, Bandung 40012 \\ "E-mail: angatin5@yahoo.com
}

\begin{abstract}
ABSTRAK
Perekat (lem) merupakan salah satu media yang sangat penting untuk menyatukan kayu yang satu dengan lainnya dan berbasis pada pelarut. Umumnya, pelarut yang digunakan adalah pelarut organik golongan BTX (Benzena, Toluene, dan Xylene) yang merupakan pelarut berbahaya bagi lingkungan dan kesehatan. Untuk itu perekat berbasis air yang berbahan baku vinil asetat akan diperkenalkan pada penelitian ini. Pengaruh hidrofobisitas surfaktan yang digunakan terhadap viskositasnya dijadikan tujuan dari penelitian ini. Vinil asetat dan polivinil alkohol digunakan sebagai bahan baku. Asam tartrat dan amonium persulfat digunakan sebagai bahan pendukung proses. Proses polimerisasi dilakukan di dalam reaktor dilengkapi kondensor, termometer, dan motor pengaduk dengan laju 50 - $500 \mathrm{rpm}$ (opsional, hingga terbentuk vorteks). Water bath dipanaskan pada tekanan 1 atm dan suhu sekitar $75^{\circ} \mathrm{C}$. Perekat yang dihasilkan dilakukan uji viskositas dan total NVC. Hasil penelitian adalah sintesis perekat melalui proses polimerisasi vinil asetat dengan polivinil alkohol berhasil dibuat, dengan hasil perekat tanpa menggunakan surfaktan memiliki viskositas (13.400 cps) di antara NP-10 (14.500 cps) dan NP-06 (5.500 cps), sehingga perekat dengan surfaktan NP-10 memiliki viskositas paling tinggi dengan nilai 14.500 cps dari ketiga perekat yang dihasilkan.
\end{abstract}

Kata kunci; Perekat berbasis air, perekat PVAc, polimerisasi PVAc, polivinil asetat.

\begin{abstract}
Adhesives (glue) is one of the important media to combine wood with another substrate based on solvent. Generally, BTX (Benzene, Toluene, and Xylene) are used as an organic solvents which are hazardous to the environment and health. For this reason, water-based adhesives made from vinyl acetate would be introduced in this study. The effect of surfactant hydrophibicity used on the viscosity was the aim of this study. Vinyl acetate, and polyvinyl alcohol were used as raw material. Tartaric acid and amonium persulfate (APS) were used as supporting materials. The polymerization process is carried out in a reactor equipped with condenser, thermometer and stirring motor with rates of 50-500 rpm (optional, until vortex created). Water bath was heated at temperature around $75^{\circ} \mathrm{C}$ with $1 \mathrm{~atm}$ pressure. The resulting adhesives were tested for viscosity and total NVC. Results of the research are the synthesis of adhesives through the process of polymerization vinyl acetate with polyvinyl alcohol were successfully done, with the result of the adhesive without surfactant has viscosity $(13,400 \mathrm{cps})$ between NP-10 (14,500 cps) and NP-06 $(5,500 \mathrm{cps})$, so that the adhesive with surfactant NP-10 has the highest viscosity with a value of $14,500 \mathrm{cps}$ of the three adhesives products resulted.
\end{abstract}

Keywords: Water-based adhesive, PVAc adhesive, PVAc homopolymerization, polyvinyl acetate 


\section{PENDAHULUAN}

Dalam dunia industri perkayuan, perekat merupakan salah satu media yang digunakan untuk menyatukan kayu satu dengan lainnya. Umumnya jenis perekat yang digunakan berbasis pelarut (solven) organik. Solven organik yang umum digunakan adalah pelarut organik golongan BTX (Benzene, Toluen, Xylene). Atas alasan pencemaran lingkungan dan kesehatan, maka lem berbasis air mulai dikenalkan. Perekat berbasis air ini bisa menggunakan bahan akrilik, dispersi poliuretan, disperse chloroprene ataupun poli(vinyl acetate).

Seiring berjalannya waktu, pelaku industri perekat berbasis air mulai meningkat dan kebutuhan perekat di industri perkayuan juga makin meningkat. Hal ini dapat dilihat dari indikator statistik yang menyatakan adanya peningkatan penggunaan perekat di Indonesia pada Gambar 1 (Kemenperin, 2014).

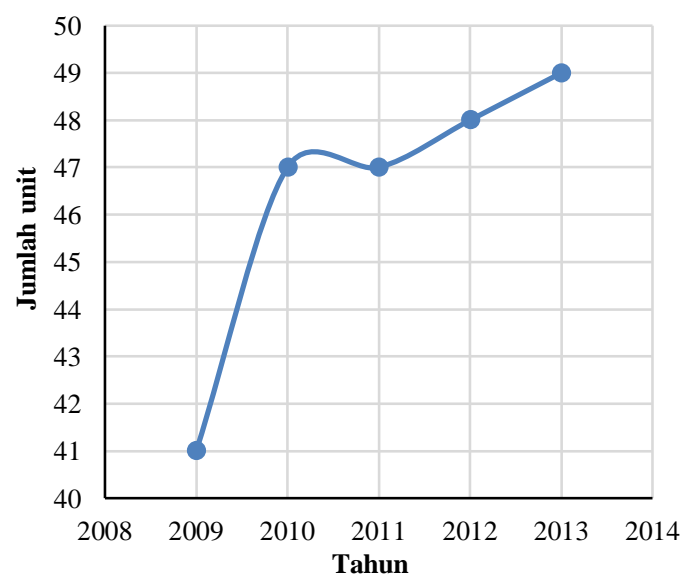

Gambar 1. Perkembangan Jumlah Unit Usaha Industri Perekat di Indonesia

Polivinil Asetat $\left(-\mathrm{CH}_{3} \mathrm{CO}_{2}=\mathrm{CH}_{2}\right)$ merupakan senyawa polimer termoplastik yang memilki sifat tahan panas, daya regang tinggi serta larut dalam pelarut organik. Pada industri Polivinil Asetat banyak digunakan sebagai bahan baku pada industri perekat, cat, Polivinil Alkohol, tekstil, kertas, dan lain-lain (Jaka, 2008). Reaksi polimerisasi pembentukan PVAc disajikan pada Gambar 2.

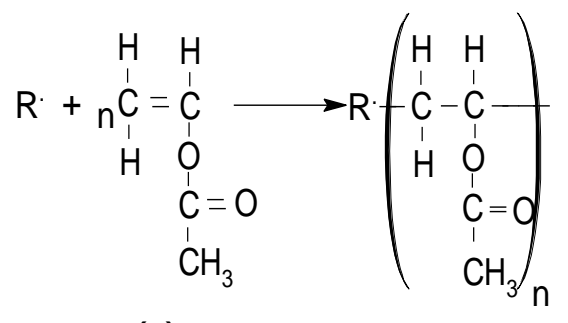

(a)

(b)

\section{Gambar 2. Proses Polimerisasi PVAc}

Proses produksi Polivinil Asetat dari monomer Vinil Asetat dengan reaksi adisi radikal bebas fase cair dalam reaktor tangki berpengaduk, karena reaksi eksotermis dan irreversible, maka dilengkapi dengan koil pendingin. Inisiator yang digunakan adalah Ammonium persulfat dan kondisi operasi pada tekanan 1 atm, suhu $75-80^{\circ} \mathrm{C}$. Sintesis homopolimer PVAc menggunakan sebuah protective koloid yang berupa Poli(vinyl alkohol) dengan tujuan untuk mencegah terjadinya aglomerasi pada proses dan mempengaruhi viskositas dalam polimer akhir. Di samping itu, jenis surfaktan juga mempengaruhi performa polimer akhir. Surfaktan non-ionik berpengaruh dalam peningkatan stabilitas kimia dan freezethaw polimer (Chern. 2006).

Surfaktan menstabilkan polimer dan tetesan monomer dengan stabilisasi elektrostatis (Klien, 1997) dan dapat juga digunakan untuk menstabilkan pertumbuhan partikel selama proses polimerisasi serta berperan sebagai chain transfer agent (CTA) (Albertson, 2007 ). Biasanya, kurang dari $6 w t \%$ surfaktan digunakan dalam polimerisasi emulsi. Jenis surfaktan yang sering digunakan dalam emulsi polimerisasi adalah nonionik dan anionik (El-Aasser, 1997). 
Dalam pembuatan homopolimer polyvinyl acetate, terkadang industri perekat menggunakan jenis surfaktan untuk mencapai tujuan tertentu. Dalam penelitian ini, jenis surfaktan nonylphenol akan digunakan dengan membandingkan panjang ikatan alkil dan melihat pengaruhnya dalam aplikasi perekat di perkayuan. Semakin panjang ikatan alkil, sifat hidrofobik semakin meningkat (anymous, 2013).

\section{METODE}

Penelitian sintesis bahan perekat ini dilakukan di laboratorium. Alat yang digunakan meliputi reaktor, termometer, water bath, kondensor, motor pengaduk, droping funel, buret. Bahan kimia yang digunakan antara lain adalah polivinil alkohol (PVOH), monomer vinil asetat (VAM), Ammonium Persulfat (APS), dan aquades.

Proses polimerisasi dilakukan di dalam reaktor dengan kondisi dialirkan gas nitrogen (inert). Laju pengadukan dilakukan 50- $500 \mathrm{rpm}$ (opsional, hingga terbentuk vorteks) dan menggunakan pemanasan dari water bath. Reaktor dilengkapi dengan kodensor, droping funel, kontrol suhu, buret dan pengaduk. Diawali dengan pembuatan larutan PVOH dengan memasukkan padatan $\mathrm{PVOH}$ dan air kemudian pengadukan dimulai dengan meningkatkan pemanasan ke suhu $80-90^{\circ} \mathrm{C}$ hingga larutan menjadi homogen. Setelah larutan PVOH selesai dibuat, suhu reaktor diatur menjadi suhu $\left( \pm 75^{\circ} \mathrm{C}-80^{\circ} \mathrm{C}\right)$. Pada suhu tersebut, surfaktan dimasukkan terlebih dahulu dan kemudian monomer vinyl acetate mulai diteteskan di awal sesuai formulasi bersamaan dengan larutan APS untuk pembentukan partikel di tahap awal. Setelah itu, tetesan monomer dimasukkan dengan tetesan APS secara bersamaan dengan waktu reaksi total \pm 3 6 jam. Setelah itu suhu diturunkan dan selanjutnya sampel disaring supaya bisa
- Pengaduk (poin 1)

- Termometer (poin 2)

- Feeding monomer (poin 3)

- Motor pengaduk (poin 4)

- Mixer / pengaduk (poin 5)

- Kondensor

- Water bath

dilakukan karakterisasi di hari berikutnya.

Karakterisasi homopolimer PVAc dalam penelitian ini meliputi pengukuran total NVC dengan menggunakan oven suhu diatas $100^{\circ} \mathrm{C}$. Kemudian karakterisasi lainnya adalah pengukuran viskositas dengan menggunakan viskometer Brookfield.

Pembuatan sintesis homopolimer PVAc awal tidak menggunakan tambahan surfaktan. Kemudian sintesis berikutnya dilakukan dengan penambahan surfaktan rantai pendek dan terakhir dilakukan dengan penambahan surfaktan rantai panjang. Secara skema alat polimerisasi dapat dilihat dari Gambar 3.

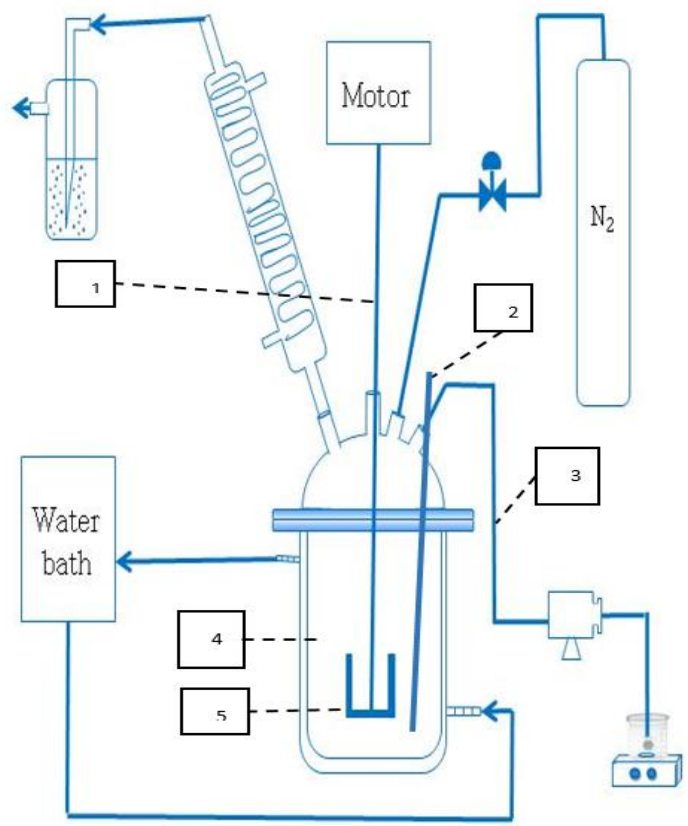

Gambar 3. Skema Alat Polimerisasi PVAc 


\section{HASIL DAN PEMBAHASAN}

Penelitian dilakukan dengan membuat 3 jenis sampel perekat melalui sintesis polimerisasi polivinil asetat. Perekat yang dibuat dapat diklasifikasikan dalam Tabel 1. Sintesis homopolimer PVAc dibuat dengan mengatur total Non Volatile Content (NVC) pada angka $\pm 35 \%$. Hasil pengukuran NVC dari ketiga sintesis homopolimer juga dapat dilihat pada Tabel 1, dimana ketiga sampel menunjukkan hasil yang relatif sama. Hal ini menunjukkan bahwa proses polimerisasi berjalan sesuai yang telah direncanakan. Dimana penggunaan surfaktan hanya sebanyak 0.1 bagian dibandingkan formula tanpa surfaktan. Dalam pengukuran total NVC, yang akan menguap adalah molekul air, sedangkan molekul vinil asetat, polivinil alkohol dan surfaktan akan menjadi solid saat molekul air menguap dan membentuk film karena homopolimer PVAc tersebut merupakan polimer berantai panjang (Fan, 2019).

\begin{tabular}{lll}
\multicolumn{3}{c}{ Tabel 1. Klasifikasi Perekat } \\
\hline $\begin{array}{l}\text { Jenis } \\
\text { perekat }\end{array}$ & Keterangan & NVC \\
\hline A & $\begin{array}{l}\text { Tanpa menggunakan } \\
\text { surfaktan }\end{array}$ & $35.02 \%$ \\
B & $\begin{array}{l}\text { Menggunakan NP- } \\
\text { 06 }\end{array}$ & $35.09 \%$ \\
C & $\begin{array}{l}\text { Menggunakan NP- } \\
\text { 10 }\end{array}$ & $35.08 \%$ \\
\hline
\end{tabular}

Viskositas merupakan parameter yang cukup penting dalam aplikasi perekat ke substratnya. Hal ini dikarenakan pada aplikasinya di lapangan, beberapa industri menggunakan bahan lunak seperti kuas, rol, dan sebagainya. Untuk aplikasi ini, diperlukan viskositas yang tidak terlalu tinggi sebagai karakterisasinya. Namun pada industri yang menggunakan perekat dengan bahan keras seperti bar, kayu keras, dan sebagainya, diperlukan perekat dengan viskositas tinggi dalam aplikasinya. Daftar viskositas yang dihasilkan pada penelitian ini dapat dilihat pada Gambar 4.

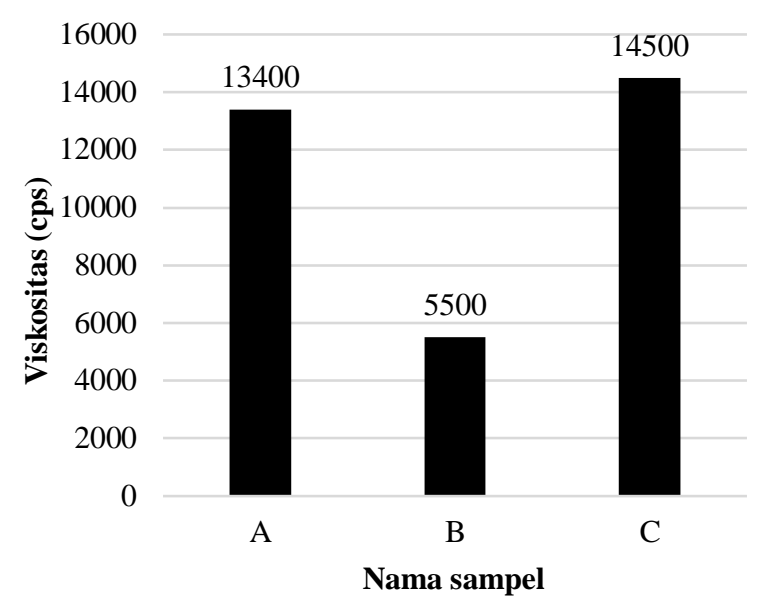

\section{Gambar 4. Nilai Viskositas Ketiga Perekat}

Dari hasil penelitian didapatkan bahwa terjadi penurunan viskositas pada homopolimer PVAc setelah penambahan surfaktan NP-06. Hal ini terjadi karena pada surfaktan NP-06 terdapat molekul etilen oksida yang bersifat hidrofilik (Royyan, 2017). Dalam polimerisasi PVAc berbasis air, molekul etilen oksida dapat bereaksi dengan senyawa alkohol dari PVOH dan juga dapat bereaksi dengan senyawa hidrogen dari air sebagaimana ditunjukkan pada Gambar 6 dan Gambar 7.Etilen oksida dapat bereaksi dengan gugus $\mathrm{OH}$ untuk membentuk etilen glikol.

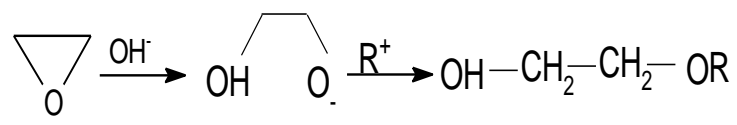

Gambar 6. Reaksi EO dengan gugus $\mathrm{OH}$

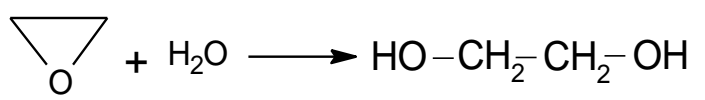

Gambar 7. Reaksi EO dengan $\mathrm{H}_{2} \mathrm{O}$

Dengan berkurangnya sifat hidrofobisitas, hal ini akan meningkatkan kemungkinan terjadinya ikatan karboksil dan hidroksil dari polimer, yang menyebabkan rantai polimer akan 
menjadi lebih pendek sehingga homopolimer ini menghasilkan viskositas yang lebih rendah sebagaimana diilustrasikan pada Gambar 8.

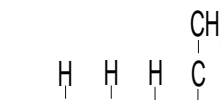

$$
\begin{aligned}
& \mathrm{H}_{3} \mathrm{C}-\mathrm{C}-\mathrm{C}_{1}-\mathrm{C}_{-}-\mathrm{C}_{1}-\mathrm{O}-\mathrm{C}-\mathrm{C}-\mathrm{C}-\mathrm{C}-\mathrm{C}-\mathrm{C}-\mathrm{C}-\mathrm{C}-\mathrm{C}-\mathrm{C}-\mathrm{C}-\mathrm{C}-\mathrm{H} \\
& \begin{array}{lllllllllll}
\mathrm{H}^{\prime} & \mathrm{CH}_{3} \mathrm{H}^{\prime} & \mathrm{CH}_{3} & \mathrm{O}^{\prime} & \mathrm{O}^{\prime} & \mathrm{O}^{\prime} & \mathrm{O}^{\prime} & \mathrm{O}^{\prime} & \mathrm{O}^{\prime}
\end{array} \\
& \mathrm{OH} \\
& \mathrm{CH}_{3} \\
& \begin{array}{llll}
H & H & H & C
\end{array} \quad O R O R \quad O R O R O R O R \\
& \mathrm{H}_{3} \mathrm{C}-\mathrm{C}_{\mathrm{C}}-\mathrm{C}-\mathrm{C}-\mathrm{C}-\mathrm{C}-\mathrm{O}-\mathrm{C}-\mathrm{C}-\mathrm{C}-\mathrm{C}-\mathrm{C}-\mathrm{C}-\mathrm{C}-\mathrm{C}-\mathrm{C}-\mathrm{C}-\mathrm{C}-\mathrm{C}-\mathrm{H} \\
& \mathrm{H} \mathrm{CH}_{3} \mathrm{H}_{3} \quad \mathrm{OH} O \mathrm{OH} O H \quad O H \quad O H O H
\end{aligned}
$$

Gambar 8. Ilustrasi Proses Surfaktan Menurunkan Sifat Hidrofobisitas PVAc

Peningkatan viskositas terjadi saat menggunakan surfaktan jenis NP-10 yang ditunjukkan pada poin $\mathrm{C}$ pada Gambar 4. Hal ini dikarenakan surfaktan NP-10 memiliki mol Etilen Oksida (EO) yang lebih banyak daripada NP-06 dan dapat dilihat pada Gambar 9. Dengan keberadaan gugus EO yang lebih banyak, akan mengakibatkan rantai polimer yang terbentuk lebih panjang dan akhirnya viskositas akan meningkat menjadi lebih tinggi. Sehingga homopolimer PVAc dengan menggunakan surfaktan NP-10 memiliki viskositas diatas homopolimer dengan surfaktan NP-06.

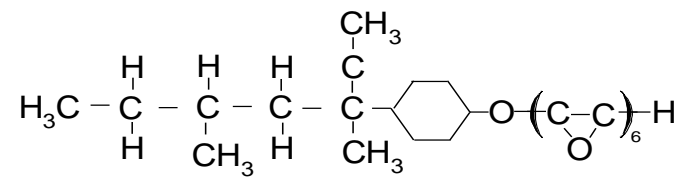

(a)<smiles>CCCCCC(C)C(C)(C)C1CCC(OC2C=CC=CC2)CC1</smiles>

(b)

Gambar 9. Perbedaan Struktur NP06 dan NP10

\section{SIMPULAN}

Sintesis homopolimer PVAc telah berhasil dilakukan dengan polimerisasi monomer vinil asetat dan $\mathrm{PVOH}$ menggunakan APS sebagai inisiatornya. Penambahan surfaktan yang bersifat hidrofilik akan mengurangi hidrofobisitas dari polimer yang akan berpengaruh pada menurunnya viskositas. Penambahan surfaktan rantai panjang juga dapat mempengaruhi peningkatan viskositas. Sintetis homopolimer tanpa menggunakan surfaktan menghasilkan viskositas 13.400 cps. Sintesis dengan penambahan surfaktan NP-06 dapat menurunkan viskositas menjadi 5500 cps, sedangkan sintesis dengan penambahan surfaktan rantai panjang (NP-10) dapat meningkatkan viskositas menjadi 14.500 cps.

Dengan adanya penelitian ini, diharapkan hasil viskositas yang dihasilkan dapat dimanfaatkan oleh para pelaku industri sintetis perekat, khususnya perekat homopolimer PVAc, baik skala kecil maupun skala besar, dengan menggunakan jenis surfaktan yang sama maupun dengan pemanfaatan hidrofobisitas dari jenis surfaktan yang lain.

\section{DAFTAR RUJUKAN}

Anymous; Nonylphenol and Nonylphenolethoxylates in Textiles; Annex XV; 2013

Albertson, Ann-Christine and coworkers, Introduction till polymerteknologi, Chapter 12, 2007

Chern C. S. 2006 Emulsion Polymerization Mechanisms and Kinetics. Progress in Polymer Science 31, 443-486.

El-Aasser, Mohamed S; Sudol, E. David, 1997 Features of Emulsion Polymerization, Chapter 2, Edited by: Lovell, Peter A; El-Aasser, Mohamed S, Emulsion 
Polymerization and Emulsion Polymers, , John Wiley \& Sons Ltd

Fan Bu. 2019. Effect of the preparation Conditions and Reinforcement Mechanism of Polyvinyl acetate Soil Stabilizer, Polymer.

Hanna Lange, 2011. Emulsion Polymerization of vinyl acetate with renewable Raw Materials as Protective Colloids.

Jaka. 2008. Laporan Tugas Prarancangan Pabrik Prarancangan Pabrik Polivinil Asetat Dari Vinil Asetat Monomer Dan Metanol Dengan Batch Solution Polymerization Process Kapasitas 50.000 Ton/Tahun. Surakarta
Kemenperin. 2014.

Royyan. 2017. Pengaruh penambahan polietilen glikol diakrilat terhadap karakteristik hidrogel film untuk aplikasi pembalut luka.

Sudarmaji, 2012. Mempelajari Pengaruh Jenis inisiator, Jenis Surfaktan dan Waktu Feeding Monomer Terhadap Kinerja Pressure Sensitive Adhesive Berbasis Air. Universitas Indonesia. 